Anniko, M. 143

Arnold, W. 114

Betka, J. 166

Böőr, A. 148

Brackmann, D.E. 138

Bretlau, P. 129

Bux, G. 73

Caye-Thomasen, P. 86

Chole, R.A. 95

Colucci, S. 73

Cureoglu, S. 65

Dal Sasso, A. 73

Ferlito, A. 108
Harris, J.P. 125

Hitselberger, W.E. 138

Hung, G. 138

Iurato, S. 73

Jenča, A. 148

Jung, J.Y. 95

Jurkovič, I. 148

Karma, P. 80

Keithley, E.M. 125

Kočan, P. 148

Linthicum, F.H., Jr. 138

Manolidis, L.S. 152

Mevoli, S. 73
Niedermeyer, H.P. 114

Onofri, M. 73

Paparella, M.M. 65

Qvortrup, K. 129

Rinaldo, A. 108

Saleh, E.S. 138

Schachern, P.A. 65

Shaha, A.R. 108

Takumida, M. 143

Tos, M. 86

Tran Ba Huy, P. 120

Veldman, J.E. 157

Zambonin, A. 73

\title{
Subject Index Vol. 64, No. 2, 2002
}

Acid phosphatase 129

Atypical carcinoid 108

Bone resorption 95

Brain herniation 73

- prolapse 73

Cholesteatoma 95

Cochlea 125

Collagen 114

Deafness, inner ear 120

Deshima 157

Dural herniation 73

Dutch Trading Company 157

Dutch-Japanese relations 157

Electron microscopy 129

Encephaloceles 73

Endolymph 120

Endolymphatic sac 129

Epithelial-myoepithelial carcinoma 148

Fluorescence 143

Gentamicin 143

Gland formation 86

Heredity 114
Hippocrates 152

Immunoprophylaxis 80

Inflammation 125

Inner ear 125

Interleukin 95

Kaempfer 157

Larynx 108

Measles virus 114

Meningoencephalic herniation 73

Middle ear 73

- - mucous glands 86

Mucosa 86

Nitric oxide 95, 143

Osteoclast 95

Osteopetrosis 95

Otitis, chronic silent 65

-, complications 65

- media, acute 80

- -, chronic 95

- -, secretory 86

-, pathology 65
Otorhinolaryngology 152

Otosclerosis 114

Ototoxicity 143

Paraganglioma 108

Parotid gland 148

Pre-Hippocratic philosophers 152

RANKL 95

Reactive oxygen species 143

Saccin 129

Salivary gland neoplasms 148

Schwannoma 138

Small cell neuroendocrine carcinoma 108

Spherulosis, collagenous 148

Spiral ligament 125

Temporal bone meningoencephalocele 73

Typical carcinoid 108

Ultrastructure 129

Vaccination 80

Vestibular nerve 138

- organ 143

von Siebold 157

\section{KARGER}

Fax +41613061234 E-Mail karger@karger.ch www.karger.com
(C) 2002 S. Karger AG, Basel

Accessible online at: www. karger.com/journals/orl 